\title{
correspondence
}

\section{Farm energy}

Sir,-I am not sure what your correspondent Michael Knee is trying to say in his letter (13 October, page 556). He accuses me of "blind prejudice" for stating a few simple facts about the use of energy by farmers. If he reads my contributions in the issues of 25 August (Frugal farming) and of 8 September (Food for energy), he will find that he has misinterpreted my views.

I would be the last to deny that an enormous amount of energy is wasted by some modern farmers, but this is almost entirely because of the inefficiency of intensively-kept livestock, which waste over $90 \%$ of their food, and which is the main reason why Britain is not already largely selfsufficient. This is mentioned in my contribution of 25 August, and explained in detail in my book Can Britain Feed Itself. But this is irrelevant to the present argument.

My contention is that arable farming is efficient. It has been shown by everyone who has investigated the situation, including Gerald Leach in his Energy and food production (mentioned by Michael Knee) that arable farming, although using much energy to propel tractors and manufacture fertilisers, produces crops with at least three times the energy value of that used in growing them. Recent developments, such as direct drilling, will reduce energy expenditure without reducing the yields, and so further improve the equation. In fact intensive arable farming is probably the most efficient way we can trap solar energy in an easily useable form.

I.ike Michael Knee, I would like to see more people working on our farms, but men, like horses, would probably use more energy in a twelve-month than the present tractors and combine harvesters, if we were to grow and harvest comparable crops. Yours faithfully, Kenneth Mellanby

Huntingdon, $U K$

\section{Desert rainfall}

Sir,--The statement by Glantz and Katz (19 May, page 192) with regard to measuring rainfall at two locations, Gao and Niamey, in the Sahel "that at least is some sense, the mean is too large and not at all indicative of how much rain commonly falls" is overly strong. In no sense is the mean too large; the mean is simply the meana well defined and much used statistic. Furthermore it is quite indicative of how much rain commonly falls in most regions-even Gao and Niamey. Glantz and Katz also note that positive "skewness is characteristic of the rainfall distribution not only in the Sahel but, more generally, in arid and semiarid regions. In particular the degree of skewness is greater the drier the climate". It has been our expcrience, however, that positive skewness is a characteristic of rainfall distribution for almost all localities and that, at most, there seems to be only a slight tendency for the degree of skewness to increase as the average amount of precipitation decreases.

We selected a random sample of fifteen reporting localities from the original Climatic Summary of the United States which contained data from the establishment of reporting stations up to 1930 . The only restrictive requirement imposed in the selection process was that there had to be at least twenty consecutive years of records for a given locality. We used the mean, standard deviation, and coefficient of skewness for the distribution of precipitation at each location to examine the hypothesis that the more arid the climate the more skewed the distribution rainfall. If the hypothesis is valid, there should be a strong negative correlation between mean rainfall and the skewness coefficient. We found that there did seem to be more skewness for regions with little rainfall in the month of July than for a region of average rainfall, but positive skewness also seemed to be greater for regions with greater than normal rainfall. The correlation coefficient of $r=-.08$ tends to confirm the lack of a simple systematic negative relationship between mean rainfall and skewness.

It also should be noted that positive skewness seems to be the normal condition for the distribution of rainfall for almost all localities and not just for the localities in arid regions. The meaning of this should be evident. If it is not true that the mean alone is suitable for describing the distribution of rainfall in arid regions, then neither is it alone a suitable measurement for describing the distribution in any region. This, however, is not a surprising result; few distribtuions can be de- scribed by one parameter. As Glantz and Katz state, "no single number can adequately describe the climate regime of an arid or semiarid region". We would add that the statement holds for all regions and not merely for arid or semiarid regions.

We also would like to add a note of disagreement with the statement that, "recent weather tends to influence perceptions more heavily than earlier weather and wet spells more heavily than dry ones". While the statement about recent weather versus earlier weather seems totally acceptable, the latter part of the statement would seem to need at least some documentation. What evidence exists to substantiate this statement? If nothing else, it does seem evident that the drought of the past few years in the Sahel will influence perceptions and behaviour quite as much as the earlier wet spells. Yours faithfully,

\section{J. LARRY DEATON}

United States Department of

Agriculture,

Washington $D C$

\section{Using varied talents}

SIR,-I was unpleasantly surprised at your negative editorial comment on Sir Andrew Huxley's Presidential Address (8 September, page 95). Accepting the idea that inherited differences exist does not automatically condemn the apparently less-endowed people to a subbuman status. Those with no apparent talent are not necessarily inferior; they simply can't find their true calling in our culture. A century ago born atomic physicists and computer programmers may have spent their lives on the skid row as impractical silly dreamers; today they are productive, well-regarded members of our society.

As civilisation advances, more and more people will find the calling that uses their innate talents; fewer and fewer will spend their lives as frustrated misfits. All we have to do is to maintain progress in our civilisation, so more and more varied talents can be used. However, to maintain this progress we must have the courage to face the apparently impalatable as well as the palatable results.

Yours faithfully,

ANDREJS BAIDINS

Du Pont Company,

Wilmington, Delaware,

USA 